\title{
BUCCAL MUCOADHESIVE FILMS
}

\author{
SINDHU G. D. , LAVANYA NALLAGUNTLA, GURURAJ S. KULKARNI \\ Department of Pharmaceutics, the Oxford College of Pharmacy, Bangalore, Karnataka 560068, India \\ *Email: gdsindhu55@gmail.com
}

Received: 05 May 2021, Revised and Accepted: 25 Jun 2021

\begin{abstract}
The buccal route of administration has many advantages, including gastrointestinal bypass surgery and first pass through the liver. The mucoadhesive membrane is a retention dosage form that can release the drug directly into the biological matrix. Cheek technology has proven to be an advanced alternative to other traditional devices. The type of drug delivery system. This is a mature technology for systemic administration of active pharmaceutical ingredients [API]. In addition, due to their small size and thinness, these films improve patient compliance. Over the past decade, because it is a promising delivery alternative for multiple therapeutic categories, including peptides, vaccines and nanoparticles. Mucosal adhesions are currently explained by six theories: electronics, adsorption, wettability, diffusion, degradation and mechanics. Various in vitro and in vivo techniques are suggested. Study its mechanism. This study includes an overview of the mechanisms and theories of mucosal adhesion, and introduces the most commonly used methods. The "film casting method" involves casting an aqueous solution and/or organic solvent to produce a film suitable for the application route. The determination of key properties such as mucosal adhesion strength, uniformity of active ingredient content and permeability are important research areas in the field of buccal membrane design.
\end{abstract}

Keywords: Buccal films, Mechanism, Preparation methods and Evaluation, Recent advancement, Experimental design

(C) 2021 The Authors. Published by Innovare Academic Sciences Pvt Ltd. This is an open access article under the CC BY license (https://creativecommons.org/licenses/by/4.0/) DOI: https://dx.doi.org/10.22159/ijcpr.2021v13i4.42735 Journal homepage: https://innovareacademics.in/journals/index.php/ijcpr

\section{INTRODUCTION}

Oral drug delivery is the preferred route of drug delivery, covering a variety of diseases that have been successfully treated. With its potential benefits, including a proven, patient-friendly, convenient, economical and non-invasive delivery system, it has become the most popular drug delivery system in the pharmaceutical industry. Several serious shortcomings related to the drug application of drugs prevent their use in certain groups of people, namely children, the elderly and the mentally ill. The oral dose for these people is sometimes restricted because the patient cannot swallow the product. In addition, there are many active pharmaceutical ingredients that are unstable under various environmental conditions and cover oral doses (from stomach acid to severe intestinal diseases) [1]. Sometimes ineffective-drugs that can only be partially absorbed by the first pass effect orally are first transported to the liver through the portal vein. Irritation of the stomach wallnausea and vomiting. The destruction of drugs by stomach acid and digestive juices. For emergencies, the effect is too slow. Some medicines taste bad. It cannot be used for unconscious patients. Oral medication can avoid decomposition under the harsh conditions of the gastrointestinal tract. In addition, the oral cavity is easy to selftreat. If a toxic reaction occurs, the oral cavity can be quickly closed by simply removing the dosage form from the oral cavity.

\section{Buccal drug delivery}

Oral drug delivery is an attractive alternative to oral drug delivery, especially overcoming related shortcomings. Through oral medication, problems such as first-pass metabolism and drug breakdown can be avoided under severe gastrointestinal conditions [2]. In addition, the oral cavity is easy to self-treat. If poisoned, the oral cavity can be quickly interrupted by simply removing the dosage form from the oral cavity. Buccal administration can also be administered to patients who cannot be administered orally via the buccal route [3].

Over the decades mucoadhesion has been popular for decades because it can optimize topical drugs by keeping the dosage form at the site of action (for example in the gastrointestinal tract) or by keeping the preparation in close contact with the active ingredient for systemic administration. The biological surface can be epithelial tissue or a layer of mucus on the surface of the tissue. When adhesion occurs with the mucus layer, this phenomenon is called mucoadhesion. Mucoadhesive polymers are more widely used for oral drug delivery [4]. Oral films or strips are made into large sheets, which are then cut into individual dosage units for packaging [5].

Buccal patch is a thin matrix composed of one or more polymer films or layers, insoluble, slow-release dosage form, containing dug and other excipients. The patch may contain a layer of mucoadhesive polymer that adheres to the lining of the oral cavity, gums or teeth in order to release the drug into the lining of the oral cavity in a controlled manner (unidirectional release), oral cavity (unidirectional release), Or both (two-way release). Take it out of your mouth and throw it away after a certain period of time. The ideal oral patch should have flexibility, resilience, softness and firmness to resist tearing caused by oral pressure. In addition, it must have good mucosal adhesion strength so that it can remain in the oral cavity for a reasonable period of time. Therefore, the mechanical, mucosal adhesion and swelling properties of oral plasters are important and necessary conditions for evaluation [6].

\section{Advantages}

Buccal films have a large surface area because they promote the systemic absorption of active pharmaceutical ingredients, leading to rapid disintegration and dissolution in the oral cavity. The membrane increases the systemic bioavailability of the drug by preventing the drug from being metabolized in the liver. Protect the drug from degradation by gastrointestinal enzymes and acids. The effect is very fast and the side effects are very small. Selfmanagement is possible. The exact dosage compared to the liquid dosage form. It is possible to cover up the taste. Increase the duration. The residence time of the dosage form at the point of absorption increases the bioavailability. It is suitable for children, the elderly, people with mental and physical disabilities, and people who refuse to work together. Convenience of transportation, storage and consumption. More economical [7].

\section{Limitations}

Drugs that irritate the mucous membrane, have a bitter or unpleasant smell, or have an unpleasant smell should not be used in this way. Drugs with unstable oral pH should not be taken in this way. The drug can only be administered in the low doses required. Therefore, it can 
be introduced through passive diffusion. In the case of oral dosage forms, intake and drinking may be restricted. Currently, patients can swallow buccal tablets. Excessive hydration can result in a smooth surface and can change the structural integrity of the composition by swelling and hydrating the bioadhesive polymer [8].

\section{TYPES}

\section{Matrix type (Bi-directional)}

The buccal patch with matrix configuration contains drugs, adhesives, the bidirectional patch (fig. 1) releases the drug into the mucosa and oral cavity.

\section{Reservoir type (one-way)}

The oral patch designed in the reservoir system contains a cavity for containing the drug and the additive separated from the adhesive. Used to control the direction of administration; reduce the deformation and decay of the patch in the oral cavity; and prevent the loss of the drug [9].

\section{Buccal mucosa}

The cheek area is naturally sticky and acts as a lubricant, so the movement between cells can reduce friction. Four sites are used for drug delivery, namely the oral cavity, the tongue area, the roof of the mouth and the gum area. The drug administration position starting from the above four positions is the buccal route. The anatomical part where drug delivery takes place between the cheek and the gums is called the buccal endometrium [10].

The oral mucosa is composed of three layers: the first layer is layered squamous epithelium, and under this layer is the basement membrane. The basement membrane overlaps its own layer and submucosa [11]. Cheek and sublingual area contains only a small amount of ceramide and is therefore more permeable than other areas of the mouth [12]. Mucoadhesive lubrication and mucoadhesion of drug delivery systems. The cheek area has a relatively firm and smooth surface, which is suitable for installing restraint systems [13]. Adhesion to the oral mucosa not only provides the proximity of contact and the ability to improve drug absorption, but also the ability to obtain the best retention time at the injection site [14]. These characteristics make the oral mucosa the most suitable site for long-term systemic administration.

\section{Oral mucosal sites}

\section{Sublingual delivery}

Sublingual Administration Mucosa (the ventral membrane of the tongue and the membrane of the bottom of the mouth in the systemic circulation).

\section{Oral administration}

The oral mucosa (buccal mucosa) enters the systemic circulation.

\section{Local delivery}

The treatment of oral diseases is mainly ulcers, fungal diseases and periodontal diseases. These areas of the oral mucosa vary greatly in anatomy and patency. The drugs used and their ability to maintain the delivery system within the expected time $[15,16]$.

\section{Mechanism of mucoadhesion}

\section{Contact between a pressure}

Sensitive adhesive material and a surface is called as adhesion. It can be defined as the state where two surfaces are connected due to valence force or interdigital action on the interface.

\section{Bio adhesion}

Bioadhesion is the adhesion of synthetic or natural materials to biological surfaces, while mucoadhesion is the adhesion of materials to mucus and/or epithelial surfaces. Mucoadhesion occurs in two stages depending on nature of dosage form and its delivery as shown in fig. 1.

\section{Stage-I (Contact stage)}

By wetting, spreading and swelling the surface of the bioadhesive, close contact between the bioadhesive and the film can be established. Sometimes additional forces like mechanical system in vaginal delivery, aero dynamics in nasal delivery and peristaltic motions in intestinal delivery of dosage form.

\section{STAGE I - Wetting and swelling of the polymer (contact angle)
STAGE II - Interpretation between the polymer chains and mucosal membrane (contact sta
STAGE III - Formation of bonds between entangled chains (consolidation stage)}

Fig. 1: Mechanism of mucoadhesion

\section{Stage II (Consolidation stage)}

Moisture breaks molecules, due to wall forces, electrostatic attraction, hydrogen bonding and hydrophobic interaction, there is mutual penetration or dominant attractive interaction between the two surfaces. In order to be completely bioadhesive, the attractive force must overcome the repulsive force. For complete Bio adhesion attractive forces must overcome repulsive forces. Consolidation step is explained by two theories:

\section{Diffusion theory}

Mucus glycol proteins interact with mucosal adhesion substances. The molecules penetrate their chains and form secondary bonds. This is a chemical and mechanical interaction.

\section{Dehydration principle}

After contact with mucus, the material is dehydrated until the osmotic pressure reaches equilibrium, forming a gel-like mixture of mucus and material [17].

\section{Different theories of mucoadhesion}

Six different theories have been proposed as given in (table 1)

\section{Design of buccal mucoadhesive dosage forms \\ Buccal tablets}

Tablets are the most widely studied formulation for trans-buccal drug delivery. The cheeks are small, flat and oval, different from ordinary tablets, allowing you to drink and talk without feeling uncomfortable. They become soft, stick to the mucous membrane and are retained inside. Leave until completely disassembled and/or approved. Bilayer matrices and monolithic tablets have been developed for buccal drug delivery.

\section{Oral patch}

Oral patch is described as a laminate that includes an impermeable backing layer, a reservoir layer containing a drug that releases the drug in a controlled manner, and a bioadhesive surface for adhesion to the mucosa. An impermeable protective layer can also be used to control the direction of drug release, prevent drug loss, and minimize the deformation and damage of the device during use.

\section{Buccal films}

For the comfort of the patient, the buccal membrane is preferable to mucosal sheets and tablets compared with gels and ointments, it is 
more flexible, can more accurately determine the drug dosage and extend the residence time [19]. The oral membrane can also reduce pain by protecting the wound surface, thereby improving the treatment effect [20].

Table 1: Mechanism of mucoadhesion [18]

\begin{tabular}{|c|c|c|c|}
\hline S. No. & Name of theory & Mechanism & Specifications \\
\hline 1 & Wetting theory & $\begin{array}{l}\text { Ability of bioadhesive polymer to spread and develop } \\
\text { intimate contact with the mucous membrane. }\end{array}$ & $\begin{array}{l}\text { Spreading coefficient of polymers must be positive. Contact } \\
\text { angle between polymer and cells must be near to zero. }\end{array}$ \\
\hline 2 & $\begin{array}{l}\text { Electronic } \\
\text { theory }\end{array}$ & $\begin{array}{l}\text { Attractive electrostatic forces between glycoprotein } \\
\text { mucin network and the bioadhesive material. }\end{array}$ & $\begin{array}{l}\text { Electrons transfer occurs between the two forming a double } \\
\text { layer of electric charge at the Surface. }\end{array}$ \\
\hline 3 & Diffusion theory & $\begin{array}{l}\text { Physical entanglement of mucin strands and flexible } \\
\text { polymer chains }\end{array}$ & $\begin{array}{l}\text { For maximum diffusion and best adhesive strength, solubility } \\
\text { parameters of the bioadhesive polymer and the mucus } \\
\text { glycoproteins must be similar. }\end{array}$ \\
\hline 4 & $\begin{array}{l}\text { Adsorption } \\
\text { theory }\end{array}$ & Surface force resulting in chemical bonding & $\begin{array}{l}\text { Strong primary force: covalent bonds. Weak secondary forces: } \\
\text { hydrogen bonds and van der Waal's forces. }\end{array}$ \\
\hline 5 & $\begin{array}{l}\text { Mechanical } \\
\text { theory }\end{array}$ & $\begin{array}{l}\text { Adhesion arises from an interlocking of liquid } \\
\text { adhesive into irregularities on the rough surface }\end{array}$ & $\begin{array}{l}\text { Rough surfaces provide an increased surface area available } \\
\text { for interaction along with an enhanced viscoelastic and plastic } \\
\text { dissipation of energy during joint failure, which are more } \\
\text { important in the adhesion process than a mechanical effect }\end{array}$ \\
\hline 6 & Fracture theory & $\begin{array}{l}\text { Analyses the maximum tensile stress developed } \\
\text { during attachment of the transmucosal DDS from the } \\
\text { mucosal surface. }\end{array}$ & $\begin{array}{l}\text { Does not require physical entanglement of bioadhesive } \\
\text { polymer chains and mucous strands, hence it is appropriate } \\
\text { to study the bioadhesion of hard polymers which lack flexible } \\
\text { chains }\end{array}$ \\
\hline
\end{tabular}

\section{Buccal gels and ointments}

These are semisolid dosage forms having the advantage of easy dispersion throughout the oral mucosa. The use of bioadhesive preparations solves the problem of poor gel retention at the application site. Some bioadhesive polymers (such as sodium carboxymethyl cellulose) undergo a phase change from liquid to semi-solid. This change increases or improves viscosity, leading to delayed or controlled drug release [21].

\section{Innovative drug delivery systems}

These comprise use of lipophilic gel, buccal spray and phospholipid vesicles to deliver peptides via the buccal route. A new liquid aerosol formulation [22] (Oralin, Generex Biotechnology Company) was recently developed and is currently under development. Phase III clinical trial. The system delivers precise doses of insulin into the oral cavity in the form of small droplets through a metered-dose inhaler. Compared with traditional technology, the level of oral drugs has risen sharply. The oral aerosol is quickly released. The sugar absorbed through the oral mucosal epithelium is absorbed and provides the plasma insulin level required to control the postprandial blood glucose increase in diabetic patients. This new painless oral insulin formulation has several advantages. These measures include rapid absorption, simple administration techniques (easy to use), precise dose control (equivalent to intraunit injection) and high-dose administration. Phospholipid deformable vesicles, transfersomes, have been developed to deliver insulin into the oral cavity. They respond to external stresses through rapid shape transformations that require little energy. Their high malleability allows them to inject drugs across the epithelial barrier. To produce these vesicles, a surfactant such as sodium cholate or sodium deoxycholate is added to the vesicle membrane. The administration of insulin to rabbits is superior to conventional liposomes: compared with subcutaneous injection of insulin solution, the bioavailability of deformable vesicles is significantly higher than that of conventional vesicles [23].

\section{Formulation aspects of buccal films}

\section{Active ingredient}

The active ingredients used in the buccal patch should have the following characteristics: The usual single dose of the drug should be low. Drugs with a biological half-life of 2 to $8 \mathrm{~h}$ are good candidates for controlled drug delivery. The maximum drug shows greater fluctuations or higher values when taken orally. When taken orally, the absorption of the drug should be passive [24].

\section{Polymers (adhesive layer)}

Bioadhesive polymers are most important in buccoadhesive drug delivery systems of drugs. A matrix device that mixes a drug with a polymer matrix that controls the release time of the drug. The ideal polymer for buccoadhesive drug delivery system should have the following characteristics [25]. It must be inert and compatible with the environment. The polymer and its decomposition products must be non-toxic and can be absorbed by the mucosal layer. It should quickly adhere to the wet tissue surface and have a certain local specificity. The polymer should not degrade during the storage or shelf life of the dosage form. The polymer must be readily available on the market and must be economical. The criteria followed in polymer selection as mentioned in table 2 .

The polymers that are commonly used as bioadhesive in pharmaceutical applications are-Tragacanth, Sodium alginate, Guar gum, Xanthan gum (Natural polymers) and Methylcellulose, Ethyl cellulose, Poly vinyl alcohol, Poly vinyl pyrrolidone, HPC, HPMC (Synthetic and semisynthetic polymers).

Table 2: Criteria followed in polymer selection [26]

\begin{tabular}{ll}
\hline S. No. & Criteria followed in polymer selection \\
\hline 1 & Non-toxic, non-irritating and free of leachable contaminants. \\
2 & It must quickly adhere to the oral mucosa and have sufficient mechanical strength. And the shear strength in the field of bioadhesive. \\
3 & Good spreadability, wettability, swelling and solubility, and biodegradability. \\
4 & Must form a strong non-covalent bond with mucin or epithelial surface. \\
5 & It must have high molecular weight and narrow distribution. \\
6 & It must be bioadhesive in both dry and liquid state. \\
7 & It must be compatible with biofilms \\
\hline
\end{tabular}

\section{Diluents, sweeteners and flavors}

Diluents, sweeteners, and flavoring agents are pharmaceutical excipients used to improve the morphological characteristics of the dosage form, such as size, taste, and smell. Since the patch is intended for oral use, taste and smell are also considered for this purpose, and aroma and sweeteners are used. The diluent is used as a filler in small doses. 
Diluents-e. g. Lactose, Microcrystalline starch, starch.

Sweetening agents-e. g. Sucralose, aspartame, mannitol

Flavoring agents-e. g. Menthol, vanillin, clove oil

\section{Backing layer}

Backing membrane plays important role in the attachment of bioadhesive devices to the mucus membrane. The materials used as carrier film should be inert, and impermeable to the drug and penetration enhancer to prevent release of it from the patch. Commonly used materials include carbopol, magnesium separate, HPMC, HPC, CMC, sodium CMC, polycarbophil and so on [27].

\section{Penetration enhancer}

Membrane penetration is the main limiting factor for many drugs to form plaques on the cheeks. The epithelium lining the oral cavity is a very effective barrier for drug absorption. The mucous membranes are called penetration enhancers. Penetration enhancers improve drug release. They also facilitate the systemic administration of drugs, making it easier to enter living tissues [27, 28]. The mechanism of action of penetration enhancers is as follows: Changes in mucus rheology. Increase the fluidity of the double-layer lipid membrane. Affect close contact of components. Overcome the enzymatic barrier. Increase the thermodynamic activity of the drug.

Example-EDTA, citric acid, sodium salicylate, methoxy salicylates (Chelators), sodium lauryl sulphate, polyoxyethylene, Benzalkonium chloride, cetylpyridinium chloride, cetyltrimethyl ammonium bromide (Surfactants), sodium glycocholate, sodium deoxy cholate, sodium taurocholate, sodium glycodeoxycholate, sodium taurodeoxycholate (Bile salts), oleic acid, capric acid, lauric acid, lauric acid/propylene glycol, methyloleate, phosphatidylcholine (Fatty acid), unsaturated cyclic ureas (Non-surfactants) and cyclodextrins (Inclusion complexes).

\section{Plasticizers}

Plasticizer is an important factor that affect mechanical properties of films. Mechanical properties such as tensile strength and elongation of films. Changed in the concentration of plasticizers will affect these properties [8]. The commonly used plasticizers are glycerol, PEG100,400 , propylene glycol, di-butylpthallate etc.

\section{Method of preparation of buccal films}

Various methods for producing oral films are classified as solvent casting, semi-solid casting, ram extrusion, screw extruder-single screw/twin screw extruder, solid dispersion extrusion and rolling method.

\section{Solvent casting method}

The oral film is mostly prepared by using the solvent-extraction method, where in water soluble substances are dissolved to shape a clean viscous solution. The active pharmaceutical component and other agents are dissolved in small quantity of solution and integrate with bulk. This combination is then added into aqueous solution. Remove entrapped air and ensuing solution is casted as film and then dried that is then reduced to portions of the preferred sizes [29].

\section{Semi solid casting}

First, a solution of water-soluble film-forming polymer is prepared by a semi-hard casting method. The resulting solution is then added to insoluble polymers, such as cellulose acetate butyrate, cellulose acetate phthalate, etc., which are made of sodium hydroxide or ammonium hydroxide. Then add the correct amount of plasticizer to make a gel. Finally, a temperature-controlled barrel is used to shape the gel mass into a film. The thickness of the film is about 015-0.05.

\section{Hot-melt extrusion}

Hot melt extrusion is a widely used method for preparing sustainedrelease granular tablets. Transdermal and transmucosal drug delivery systems. The film includes the use of a heating process to form the polymer into a film. The funnel is filled with the drug carrier mixture and transported through the extruder, mixed and melted. The melt is then converted into the desired film in the form of a matrix [30]. Pharmaceutical Hot-Melt Extrusion [31] processes can be divided into ram extrusion or screw extrusion. Screw Extruders are of two types-Single Screw Extruder and Twin-Screw Extruders.

\section{Ram extrusion}

It works with a piston, which can generate high pressure to force the material through the mold. During the extrusion of the piston, the material is fed into the heated cylinder. After a period of induction softens the material, the piston (or piston) pumps the soft material through the nozzle and transforms it into the desired shape. The principle of piston extrusion is high pressure. The main disadvantage of piston extrusion over extrudates. The meltability of the processed screw extrudate is limited, which results in poor temperature uniformity of the extrudate and leads to lower uniformity.

\section{Single screw extruder}

It is the most widely used extrusion system in the world. The screw rotates in the rod for feeding, melting, vacuuming and pumping. Feeding on rivers or hunger, depending on the expected production process. The single screw extruder is a continuous high pressure pump. Used for melting and mixing viscous materials that can generate thousands of pounds of pressure. The single screw extruder has three main functions: solid handling, melting and pumping. The movement of the solid at the beginning of the screw is the result of friction. Between the material and the hole in the feed section. After the solid is transported, the flight depth begins to decrease, and the heated cylinder causes the formation of a melt. Heater and scissors help to melt. Ideally, the melt pool will increase as the size of the solid layer decreases, until everything melts at the end of the compression zone. Finally, the molten material is pumped against the resistance of the die to form an extrudate.

\section{Twin-screw extruders}

This method has many advantages over single-screw extruder, such as: Material supply is easier, mixing and dispersing ability is high, and the possibility of overheating and shortening is lower. As the name suggests, twin screw extruders use two screws, usually next to each other. In a twin-screw extruder, the screw can rotate in one direction (same direction rotating extruder) or in the opposite direction (counter-rotating extruder). When a very high shear section is required, a pivot design can be used, because when the material is compressed through the gap between the two screws when connected, they will cause the material to withstand high cutting forces. In addition, the design of the extruder allows for the final dispersion of the particles. Counter-rotating twin-screw extruders usually have disadvantages such as air entrainment, high pressure generation, and low maximum screw speed and productivity.

\section{Solid-dispersion extrusion}

In this process, the drug is first dissolved in a suitable liquid solvent, and then this solution is introduced into the PEG melt at a temperature below $70{ }^{\circ} \mathrm{C}$. The selected solvent or drug cannot be mixed with the PEG melt. The polymorphism of the precipitated drug in the solid dispersion can be affected by the solvent [32].

\section{Rolling method}

In rolling method, a film is formed by preparing a premix, adding active ingredients and then forming a film. The premix contains filmforming polymers, polar solvents and other ingredients (except API). API has been added to the master batch feed tank. The charge is delivered from the first metering pump and control valve. The required amount of drug is added to the mixer and then mixed for a sufficient time to form a homogeneous matrix. Substrate and media using platen rollers [33].

\section{Evaluation}

\section{Thickness and weight uniformity}

The thickness of each patch, measured at different positions of the patch with a thickness gauge, standard screw gauge or electronic digital micrometer, and calculate the average [34]. Cut the patch into $1 \times 1 \mathrm{~cm} 2$ or $10 \mathrm{~mm}$. The weight of each patch and calculate the weight change. 


\section{Swelling studies}

Conducting a swelling index study to examine and compare the hydration properties of film polymers. The membranes were weighed separately (referred to as w1) and placed in a petri dish containing a phosphate buffer with a $\mathrm{pH}$ of 6.8. Take out samples from the petri dish at regular intervals $(5,10,15,20,25,30,35,40$, $60 \mathrm{~min}$ ), and carefully remove excess water with filter paper [35]. Weigh the swollen film again (w2). Use the following formula to calculate the swelling index of each system:

$$
\text { Swelling index }=\mathrm{W}_{2}-\mathrm{W}_{1} / \mathrm{W}_{1} * 100
$$

\section{Folding endurance}

Folding endurance of the patches was determined by repeatedly folding one patch at the same place till it broke or folded up to 300 times manually, which was considered satisfactory to reveal good patch properties. The number of times of patch could be folded at the same place without breaking gave the value of the folding endurance. This test was done on five patches.

\section{Surface $\mathbf{p H}$}

Determine the surface $\mathrm{pH}$ of the patch to study the possibility of side effects due to changes in $\mathrm{pH}$ in the body, because acidic or alkaline $\mathrm{pH}$ can irritate the oral mucosa. Place the test patch in a petri dish, moisten it with $0.5 \mathrm{ml}$ of distilled water, and store it for $30 \mathrm{~s}$. The $\mathrm{pH}$ is measured after the $\mathrm{pH}$ meter electrode is in contact with the surface [36].

\section{Bioadhesive strength}

It refers to the mechanical strength of the system. A bioadhesion strength test is performed to check the residence time of the patch at the application site. The tensile strength required to peel the bioadhesive plaster from the mucosal surface is given as a parameter of the bioadhesive properties. The pig cheek pouch can be used as the model surface for the bioadhesion test. After cutting the cheek pocket and trimming it evenly, rinse with simulated saliva. Then use it immediately [37].

\section{Drug content}

Use a magnetic stirrer to dissolve the prepared buccal patch in 100 $\mathrm{ml}$ of appropriate phosphate buffered saline (PBS) for $12 \mathrm{~h}$, and then sonicate for $30 \mathrm{~min}$ to accommodate the required amount of the drug to be tested. After filtering to remove the insoluble residue, 1 $\mathrm{ml}$ of the filtrate was diluted to $10 \mathrm{ml}$ with a suitable $\mathrm{pH}$ phosphate buffer. Measure the absorbance with an ultraviolet spectrophotometer. Record the percentage of drug in all preparations $[37,38]$.

\section{Measurement of tensile strength and percentage elongation}

A tester with a $5 \mathrm{~kg}$ load cell was used to evaluate the mechanical performance. Film strips with special dimensions and no bubbles were used. The unevenness is held between two clamps $3 \mathrm{~cm}$ apart. During the measurement, the strip is pulled through the upper clamp at a speed of $100 \mathrm{~mm} / \mathrm{min}$, and then the force and elongation at break of the film are measured. The results of the film samples in parentheses and not between the parentheses are not included in the calculation. Each film is measured in triplicate. Two mechanical properties TS and \% $\mathrm{E} / \mathrm{B}$ are calculated to evaluate.

Tensile strength= breaking strength/initial sample concentration $\left(\mathrm{mm}^{2}\right)$.

Percent elongation $=$ original length $/$ increase in length $* 100$

\section{In vitro release study}

Cut out $2 \times 2 \mathrm{~cm} 2$ and fix it on a microscope slide with a few drops of phosphate buffer (pH 6.8). The slide was fixed in a $250 \mathrm{ml}$ beaker containing $100 \mathrm{ml}$ of phosphate buffer solution (pH 6.8) at an angle of $45{ }^{\circ} \mathrm{C}$. Place the beaker in a circulating water bath maintained at $37^{\circ} \mathrm{C}$. Choose a stable system to eliminate the effect of turbulence on the release rate, take regular samples after removing the slide from the beaker, stir the solution with a glass rod, and take out $5 \mathrm{ml}$ of the sample with a graduated pipette. The end is connected to a fiberglass tube (such as a filter). The slide was quickly put back into the glass. Change the $5 \mathrm{ml}$ buffer immediately and cover the beaker with a petri dish to prevent the liquid from evaporating. Take samples every $10 \mathrm{~min}$ for $90 \mathrm{~min}$ and analyze the content of active ingredients. Analyze the collected samples by spectrophotometry at $235.5 \mathrm{~nm}$ and $264.5 \mathrm{~nm}$ with appropriate diluents, and measure the optical density of the samples using a spectrophotometer. UV-visible spectrophotometer [39].

\section{In vitro diffusion study}

In vitro diffusion study was performed using a modified Franz diffusion cellophane membrane. Phosphate buffered saline (PBS) with $\mathrm{pH} 6.8$ was used as the medium for diffusion studies. A patch with a size of $1 \times 1 \mathrm{~cm} 2$ is placed on the membrane, which is placed between the donor and recipient Franz compartments. The cellophane membrane was brought into contact with PBS pH 6 in the receptor compartment. The temperature was kept at $37^{\circ} \mathrm{C}$ while stirring at $50 \mathrm{rpm}$ using a magnetic bead stirrer. Take out $1 \mathrm{ml}$ sample from the receiving chamber within the specified range and replace it with fresh PBS with $\mathrm{pH}$ 6.8. Under the appropriate dilution, use an ultraviolet-visible spectrophotometer to measure the optical density of the sample at the appropriate wavelength [40].

\section{Ex vivo permeability study}

The diffusion and penetration rate of film containing drug through the pig cheek mucosa and their penetration through the pig mouth mucosa can be performed using the Franz diffusion cell. The effective diffusion area is $1.8 \mathrm{~cm}^{2}$, the receptor compartment $(40 \mathrm{ml})$ was filled with $\mathrm{pH} 6.8$, and its temperature kept it at $37 \pm 0{ }^{\circ} \mathrm{C}$. Use an electromagnetic stirrer to stir at $50 \mathrm{rpm}$ at $5{ }^{\circ} \mathrm{C}$ to simulate the oral environment. A $1 \times 1 \mathrm{~cm}^{2}$ patch was placed on the surface of the goat cheek mucosa located between the donor and recipient compartments of the diffusion cell. Regularly samples were collected from the receiving medium and immediately replace them with an equal volume of $\mathrm{pH} 6.8$ phosphate buffer solution. A UV-Visible spectrophotometer was used to quantify the amount of drug released into the receptor medium at the appropriate nm relative to the blank value [41].

\section{Kinetic analysis}

In order to analyze the kinetic mechanism of the drug release rate in the dosage form, the data was corrected. The obtained value is corrected to the percentage of cumulative drug release. For zeroorder kinetics, the relationship between the average value (CDR) and time; for first-order kinetics, the relationship between the remaining $\log \mathrm{R}$ and time; for the Higuchi model, the square root of $\mathrm{R}$ versus time; for the Korsmeyer model, Log $\mathrm{R}$ versus Log $\mathrm{t}$ to get the $\mathrm{R}^{2}$ value [42]

\section{Stability studies}

After discovering the active ingredients, start and end trials for the drug. The U. S. Food and Drug Administration (FDA) and the International Conference on Harmonization (ICH) have defined guidelines for stability testing of new drugs as the technical requirements for the registration of drugs for human use. The instructions indicate that the long-term stability test should be performed at $25{ }^{\circ} \mathrm{C} / 60 \%$ (relative humidity) relative humidity. The stress test should be performed at $40{ }^{\circ} \mathrm{C} / 75 \%$ relative humidity for 6 mo. If significant changes occur under these pressure conditions, the formulation should be tested under intermediate conditions.30 ${ }^{\circ} \mathrm{C} / 75 \% \mathrm{RH}$ In this study, stability studies were conducted at two different temperatures, namely the cooling temperature $\left(2 \pm 8{ }^{\circ} \mathrm{C}\right)$ and the ambient temperature $\left(25 \pm 30^{\circ} \mathrm{C}\right)[41,42]$.

\section{Use of experimental designs in development of buccal films}

Mucoadhesive buccal films have been evolved using the of tamarind seed xyloglucan (TSX) as novel mucoadhesive polysaccharide polymer for systemic delivery of rizatriptan benzoate via buccal path. Formulations have been organized primarily based totally on $3^{2}$ factorial design with concentrations of TSX and Carbopol 934P (CP) as independent variables. Three dependent variables taken into consideration have been tensile energy, bioadhesion pressure and drug launch. DSC evaluation discovered no interplay among drug and polymers. Results revealed that bilayer film containing $4 \%$ (w/v) TSX 
and $0.5 \%(\mathrm{w} / \mathrm{v}) \mathrm{CP}$ within side the drug layer and $1 \%(\mathrm{w} / \mathrm{v})$ ethyl cellulose in backing layer established diffusion of $93.45 \%$ via the porcine buccal mucosa. Thus, this study shows that tamarind seed polysaccharide can act as a potential mucoadhesive polymer for buccal delivery of a soluble drug like rizatriptan benzoate [43]

A formulation was evolved to symbolize buccal films primarily based totally on pectin and gellan gum in order to assess the potential use of those herbal polymers in the manufacturing of pharmaceutical dosage forms for controlled release of TA within the oral mucosa. Using a $2^{3}$ full factorial design, 8 formulations had been organized with the aid of using solvent casting method. The raw materials and films had been characterized the usage of techniques such as FTIR, DSC, and TG. In addition, thickness, mechanical residences, mucoadhesive power, swelling, drug content, and dissolution profile of the films had been evaluated. The outcomes of FTIR, DSC, and TG confirmed that new chemical species aren't formed in the manufacturing of films, and that those dosage forms have an adequate thermal conduct. All components confirmed a high degree of swelling, desirable mechanical resistance and elasticity, and a good mucoadhesive strength in addition to a good controlled release system [44].

\section{Recent innovations and research in buccal films}

Preis $\mathrm{M}$ et al., investigated different approaches to the manufacture of bilayer films and to study their properties residences with the aid of using special characterization techniques inclusive of an optimized experimental setup for the examine of drug release from bilayer films. Two techniques (double-casting and pasting) had been determined as appropriate techniques for bilayered film production. Results from drug release experiments indicated that slowly eroding hypromellose backing layer films discovered the best protective of the drug-loaded layer to permit unidirectional drug release, the production of bilayered films with the described techniques became possible [45]. Alopaeus JF et al., used self-forming micellar solubilizers as the film matrix, especially the use of graft copolymers (Soluplus $®$ ) as solubilizers and film-forming agents to supplement the film-forming agents with higher performance to produce buccal films. It has hydrophilicity and known mucosal adhesion; hydroxypropyl methyl cellulose (HPMC) or hydroxypropyl modified pea starch (Lycoat $\left.{ }^{\circledR}\right)$. The film is made by solvent casting. The obtained HPMC-containing dual polymer film exhibits superior corrosion resistance and mucosal adhesion performance than the single polymer control film. Proven that it is possible to easily and inexpensively prepare a dry, solid, bipolymer film containing an improved drug delivery system [46].

Chan SY et al., used rice starch as a biopolymer to rice starch is used as a biopolymer to make a film for drug delivery. The rice starch film containing model drug paracetamol and plasticizer (glycerol or sorbitol) is formed by casting. They studied the effects of plasticizers and drug loading on the drug release structure of rice starch films, and they have not yet conducted research. The physicochemical properties of the obtained rice film, including swelling and dissolution studies, were characterized. As the drug loading increases, the swelling pattern of the rice film plays a major role in the release of the crystalline form of the active ingredient [47].

\section{CONCLUSION}

In the past few decades, research in the field of oral drug delivery has shown amazing growth and progress. The transmucosal route is becoming more and more popular due to its significant advantages, for example, on the skin, prevents first-pass metabolism in the liver and first-pass excretion in the gastrointestinal tract. Such delivery is expected to be effective in oral treatment of ineffective oral drugs, and is a viable and attractive alternative to effective non-invasive delivery of protein drugs and peptide molecules. In today's global situation, scientists are looking for ways to develop oral adhesive systems using different methods to improve the bioavailability of oral drugs. The future development direction of oral glue lies in vaccine formulations. The system can play an increasingly important role in the development of new drugs. Efforts should be made to develop standard biological models in vitro and ex vivo to characterize and compare the ability of various materials and formulations to promote drug absorption through buccal route.

\section{FUNDING}

Nil

\section{AUTHORS CONTRIBUTIONS}

All the authors have contributed equally.

\section{CONFLICT OF INTERESTS}

\section{Declared none}

\section{REFERENCES}

1. Patel MR, Patel RB, Thakore SD. Nano emulsion in drug delivery. In: Applications of nanocomposite materials in drug delivery; 2018. p. 667-700.

2. Verma P, Thakur AS, Deshmukh K, Jha AK, Verma S. Routes of drug administration. Int J Pharm Studies Res 2010;1:54-9.

3. Saxena A, Tewari G, Saraf SA. Formulation and evaluation of mucoadhesive buccal patch of acyclovir utilizing inclusion phenomenon. Brazilian J Pharm Sci 2011;47:887-97.

4. Koyi PK, Khan AB. Buccal patches: a review. Int J Pharm Sci Res 2013;4:83.

5. Mahboob MB, Riaz T, Jamshaid M, Bashir I, Zulfiqar S. Oral films: a comprehensive review. Int Curr Pharm J 2016;5:111-7.

6. Ramteke KH, Dighe PA, Kharat AR, Patil SV. Buccal patches-a review. Int J Pharm 2014;4:297-308.

7. Madhavi BR, Murthy VS, Rani AP, Kumar GD. Buccal film drug delivery system-an innovative and emerging technology. J Mol Pharm Org Process Res 2013;1:2.

8. Mishra S, Kumar G, Kothiyal P. A review article: recent approaches in buccal patches. Pharma Innovation 2012;1:1.

9. Parmar HG, Jain JJ, Patel TK, Patel VM. Buccal patch: a technical note. Int J Pharm Sci Rev Res 2010;4:178-82.

10. Senel S, Ikinci GU, Kas S, Yousefi Rad A, Sargon MF, Hıncal AA. Chitosan films and hydrogels of chlorhexidine gluconate for oral mucosal delivery. Int J Pharm 2000;193:197-203.

11. Singh S, Jain S, Muthu MS, Tiwari S, Tilak R. Preparation and evaluation of buccal bioadhesive films containing clotrimazole. AAPS PharmSciTech 2008;9:660-7.

12. Danckwerts MP. Intraoral drug delivery. Am J Drug Delivery 2003;1:171-86.

13. Squier CA. The permeability of oral mucosa. Crit Rev Oral Biol Med 1991;2:13-32.

14. Shojaei AH. Buccal mucosa as a route for systemic drug delivery: a review. J Pharm Pharm Sci 1998;1:15-30.

15. Shojaei AH. Buccal mucosa as a route for systemic drug delivery: a review. J Pharm Pharm Sci 1998;1:15-30.

16. Senel S, Kremer M, Katalin N, Squier C. Delivery of bioactive peptides and proteins across oral (buccal) mucosa. Curr Pharm Biotechnol 2001;2:175-86.

17. Rajaram DM, Laxman SD. Buccal mucoadhesive films: a review. Syst Rev Pharm 2017;8:31.

18. Verma S, Kaul M, Rawat A, Saini S. An overview on buccal drug delivery system. Int J Pharm Sci Res 2011;2:1303.

19. Khairnar A, Jain P, Baviskar D, Jain D. Developmement of mucoadhesive buccal patch containing aceclofenac: in vitro evaluations. Int J PharmTech Res 2009;1:978-81.

20. Arakawa Y, Kawakami S, Yamashita F, Hashida M. Effect of lowmolecular-weight $\beta$-cyclodextrin polymer on release of drugs from mucoadhesive buccal film dosage forms. Biol Pharm Bull 2005;28:1679-83.

21. Wong C, Yuen K, Peh K. Formulation and evaluation of controlled release Eudragit buccal patches. Int J Pharm 1999;178:11-22.

22. Modi $P$, Mihic M, Lewin A. The evolving role of oral insulin in the treatment of diabetes using a novel RapidMist ${ }^{\mathrm{TM}}$ system. Diabetes/Metab Res Rev 2002;18:S38-42.

23. Yang TZ, Wang XT, Yan XY, Zhang Q. Phospholipid deformable vesicles for buccal delivery of insulin. Chem Pharm Bull 2002;50:749-53.

24. Shojaei AH, Li X. In vitro permeation of acyclovir through porcine buccal mucosa. In: Proceedings of international symposium on controlled release of bioactive materials; 1996. p. 507-8.

25. Manganaro AM, Wertz PW. The effects of permeabilizers on the in vitro penetration of propranolol through porcine buccal epithelium. Military Med 1996;161:669-72. 
26. Patil SB, Murthy RS, Mahajan HS, Wagh RD, Gattani SG. Mucoadhesive polymers: means of improving drug delivery. Pharma Times 2006;38:25-8.

27. Salamat Miller N, Chittchang M, Johnston TP. The use of mucoadhesive polymers in buccal drug delivery. Adv Drug Delivery Rev 2005;57:1666-91.

28. Smart JD. Buccal drug delivery. Expert Opinion Drug Delivery 2005;2:507-17.

29. Mahboob MB, Riaz T, Jamshaid M, Bashir I, Zulfiqar S. Oral films: a comprehensive review. Int Curr Pharm J 2016;5:111-7.

30. Nagaraju T, Gowthami R, Rajashekar M, Sandeep S, Mallesham $\mathrm{M}$, Sathish $\mathrm{D}$, et al. Comprehensive review on oral disintegrating films. Curr Drug Delivery 2013;10:96-108.

31. Reddy PC, Chaitanya KS, Rao YM. A review on bioadhesive buccal drug delivery systems: current status of formulation and evaluation methods. DARU J Pharm Sci 2011;19:385.

32. Ravindran CA. Pelagia research library. Der Pharm Sin 2011;2:218-40.

33. Mahboob MB, Riaz T, Jamshaid M, Bashir I, Zulfiqar S. Oral films: a comprehensive review. Int Curr Pharm J 2016;5:111-7.

34. Ramesha Chary RB, Vani G, Rao YM. In vitro and in vivo adhesion testing of mucoadhesive drug delivery systems. Drug Dev Industrial Pharm 1999;25:685-90.

35. Pankil AG, Patel MR, Patel KR, Patel NM. A review article on mucoadhesive buccal drug delivery system. Int J Pharm Res Dev 2011;3:121-9.

36. Vasantha PV, Puratchikody A, Mathew ST, Balaraman AK. Development and characterization of Eudragit based mucoadhesive buccal patches of salbutamol sulfate. Saudi Pharm J 2011;19:207-14.

37. Birudaraj R, Berner B, Shen S, Li X. Buccal permeation of buspirone: mechanistic studies on transport pathways. J Pharm Sci 2005;94:70-8.

38. Harris D, Robinson JR. Bioadhesive polymers in peptide drug delivery. Biomaterials 1990;11:652-8.
39. Gandhi SD, Pandya PR, Umbarkar R, Tambawala T, Shah MA. Mucoadhesive drug delivery systems-an unusual maneuver for site specific drug delivery system. Pharm Sci Monitan Int J Pharm Sci 2011;2:132-52.

40. Abruzzo A, Bigucci F, Cerchiara T, Cruciani F, Vitali B, Luppi B. Mucoadhesive chitosan/gelatin films for buccal delivery of propranolol hydrochloride. Carbohydrate Polymers 2012;87:581-8.

41. Patil BS, Tate SS, Kulkarni U, RC H WG. Development and in vitro evaluation of mucoadhesive buccal tablets of Tizanidine hydrochloride using natural polymer xanthan gum. Int J Pharm Sci 2011;8:140-6.

42. Elkayam R, Friedman M, Stabholz A, Soskolne AW, Sela MN, Golub L. Sustained release device containing minocycline for local treatment of periodontal disease. J Controlled Release 1988;7:231-6.

43. Avachat AM, Gujar KN, Wagh KV. Development and evaluation of tamarind seed xyloglucan-based mucoadhesive buccal films of rizatriptan benzoate. Carbohydrate Polymers 2013;91:537-42.

44. Fernandes FP, Fortes AC, da Cruz Fonseca SG, Breitkreutz J, Ferraz HG. Manufacture and characterization of mucoadhesive buccal films based on pectin and gellan gum containing triamcinolone acetonide. Int J Polymer Sci 2018;1:2018.

45. Preis M, Woertz C, Schneider K, Kukawka J, Broscheit J, Roewer $\mathrm{N}$, Breitkreutz J. Design and evaluation of bilayered buccal film preparations for local administration of lidocaine hydrochloride. Eur J Pharm Biopharm 2014;86:552-61.

46. Alopaeus JF, Hellfritzsch M, Gutowski T, Scherließ R, Almeida A, Sarmento B, et al. Mucoadhesive buccal films based on a graft co-polymer-a mucin-retentive hydrogel scaffold. Eur J Pharm Sci 2020;142:105142.

47. Chan SY, Goh CF, Lau JY, Tiew YC, Balakrishnan T. Rice starch thin films as a potential buccal delivery system: effect of plasticiser and drug loading on drug release profile. Int J Pharm 2019;562:203-11. 